\title{
Identifikasi Faktor-Faktor Penyebab Change Order pada Proyek Konstruksi Jalan di Sumatera Barat
}

\author{
Mafriyal Muluk', Merley Misriani' ${ }^{2}$, Jajang Atmaja ${ }^{3)}$, Syaifullah Ali $^{4)}$, Mona Monica ${ }^{5)}$ \\ 1), 2), 3), 4) Staf Pengajar Jurusan Teknik Sipil Politeknik Negeri Padang,Kampus Limau Manis \\ 5) Mahasiswa Jurusan Teknik Sipil Politeknik Negeri Padang,Kampus Limau Manis \\ email :mafriyalmuluk60@gmail.com, merlymisriani@yahoo.com, jajang.atmaja@ymail.com, \\ Syaifullahali[at]pnp.ac.id, Monamonica190596@gmail.com
}

\begin{abstract}
Abstrak
Change order sering terjadi pada proyek konstruksi jalan yang disebabkan oleh faktor planning dan desain, faktor kondisi alam, faktor pengaruh owner, faktor pengaruh kontraktor, dan faktor penyebab lain. Penelitian ini bertujuan untuk mengetahui faktor-faktor penyebab change order yang dialami oleh pihak kontraktor, untuk mengetahui faktor dominan penyebab change order yang dialami oleh pihak kontraktor, dan untuk mengetahui besar pengaruh change order pada proyek konstruksi jalan di Sumatera Barat.
\end{abstract}

Penelitian ini menggunakan metode kuantitatif. Penelitian ini ditujukan kepada kontraktor yang terdaftar sebagai anggota GAPENSI (Gabungan Pelaksana Konstruksi Nasional Indonesia) yang kantornya berada di kota Padang dan pernah mngerjakan proyek jalan di Sumatera Barat. Pengumpulan data dilakukan dengan penyebaran kuesioner kepada kontraktor yang berpengalaman dilapangan dengan kualifikasi M1,M2. Pengolahan data dalam penelitian ini menggunakan bantuan program komputer SPSS (Statistical ProductandServiceSolution) yaitu dengan uji validitas, reliabilitas, korelasi pearson product moment, dan analisa deskriptif.

Hasil penelitian menunjukkan bahwa faktor-faktor penyebab change order yang dialami oleh kontraktor pada proyek konstruksi jalan di Sumatera Barat adalah ketidaksesuaian antara gambar dan kondisi lapangan, terjadinya longsor, percepatan waktu pelaksanaan pekerjaan karena permintaan owner agar cepat selesai, dan permasalahan pembebasan lahan.

Faktor dominan yang terjadi pada proyek konstruksi jalan di Sumatera Barat adalah ketidaksesuaian antara gambar dan kondisi lapangan dengan besar pengaruhnya 88\%. Hasil pengujian ini diharapkan dapat menginformasikan kepada kontraktor agar dijadikan masukan untuk meminimalisir terjadinya change order pada proyek konstruksi jalan di Sumatera Barat.

Kata kunci: SPSS (Statistical ProductandServiceSolution), change order, faktor dominan, besar pengaruh.

\begin{abstract}
Change orders often occur in road construction projects caused by planning and design factors, natural conditions factors, owner influence factors, contractor influence factors, and other factors. This study aims to determine the factors that cause change orders experienced by the contractor, to find out the dominant factor of change order experienced by the contractor, and to determine the effect of change order on the road construction project in West Sumatra.

This study uses quantitative methods. This study was addressed to contractors who are registered as members of GAPENSI (Indonesian National Construction Executing Association) whose offices are located in the city of Padang and have carried out road projects in West Sumatra. Data collection is done by distributing questionnaires to experienced contractors in the field with M1, M2 qualifications. Data processing in this study uses the help of the SPSS computer program (Statistical Product and Service Solution), namely by testing the validity, reliability, Pearson product moment correlation, and descriptive analysis.

The results showed that the change order causes experienced by the contractor in the road construction project in West Sumatra were a discrepancy between the picture and field conditions, the occurrence of landslides, the speed of execution of the work due to the owner's request to finish quickly, and the problem of land acquisition. The dominant factor that occurs in road construction projects in West Sumatra is the discrepancy between images and field conditions with a large influence of $88 \%$. The test results are expected to inform the contractor to be used as input to minimize the change order in the road construction project in West Sumatra.
\end{abstract}

Keywords: SPSS (Statistical Product and Service Solution), change order, dominant factor, influence size. 


\section{PENDAHULUAN}

Change order sudah menjadi hal umum yang terjadi pada proyek konstruksi di Indonesia, baik proyek konstruksi yang ditangani adalah milik swasta maupun negeri. Proyek jalan di Sumatera Barat bisa saja mengalami permasalahan perubahan pekerjaan, penambahan, dan pengurangan pekerjaan. Permasalahan change order ini tidak bisa dihindari ataupun diabaikan begitu saja, karena penanganan change order benar-benar harus di selesaikan dengan tepat.

Selama pelaksanaan konstruksi change order dapat terjadi dari pihak owner, pihak kontraktor, dan juga disebabkan oleh kondisi lapangan yang tidak memungkinkan untuk dilanjutkan dalam proses pelaksanaan proyek konstruksi jalan. Change order yang meliputi pekerjaan tambah kurang, pengubahan jadwal pelaksanaan pekerjaan, dan perubahan spesifikasi teknis pekerjaan yang mempengaruhi kinerja suatu proyek konstruksi akan memberikan dampak negatif secara langsung maupun tidak langsung, baik bagi owner maupun kontraktor sendiri, (Beatrix dkk, 2014).

Dampak negatif secara langsung yang ditimbulkan dari change order itu sendiri adalah pembengkakan biaya baik itu penambahan biaya setiap item pekerjaan karena penambahan volume pekerjaan dan peningkatan biaya tenaga kerja, terjadinya peningkatan pengeluaran tidak terduga, dan terjadinya permasalahan dalam penjadwalan pelaksanaan pekerjaan.

Sedangkan dampak change order secara tidak langsung dapat berupa perselisihan yang terjadi antara kontraktor dan owner.

Change order ini membutuhkan proses untuk menyelesaikannya dan penanganan yang tepat.
Pihak-pihak yang terlibat dalam proses ini benar-benar mencari solusi yang tepat supaya tidak terjadi lagi change order yang akan mengakibatkan kerugian yang tidak diinginkan.

Tujuan penelitian ini adalah:

1. Untuk mengetahui faktor-faktor penyebab terjadinya change order pada proyek konstruksi j a I a n d S S matera Barat. 2. Untuk mengetahui faktor dominan yang mempengaruhi penyebab terjadinya change order pada proyek konstruksi jalan di Sumatera Barat.

3. Untuk mengetahui seberapa besar pengaruh change order terhadap proyek konstruksi jalan di Sumatera Barat.

Oleh sebab itu, untuk meminimalir terjadinya change order, maka dilakukan identifikasi faktofaktor penyebab change order pada konstruksi jalan di Sumatera Barat dengan cara menyebarkan kuesioner kepada kontraktor yang pernah mengerjakan proyek jalan di Sumatera barat sepuluh tahun terakhir, yang kantornya terdapat dikota Padang dan terdaftar sebagai anggota GAPENSI (Gabungan Pelaksanan Konstruksi Nasonal Indonesia)

\section{TINJAUAN PUSTAKA}

Change order adalah persetujuantertulis untuk memodifikasi, menambah atau memberi alternatif pada pekerjaan yang telah diatur dalam dokumen kontrak antara pemilik dan kontraktor, dimana perubahan tersebut dapat di pertimbangkan untuk masuk dalam ruang lingkup proyek yang asli / orisinil, dan merupakan satu-satunya cara yang sah.

Change order terdapat dua tipe perubahan yaitu Direct Change (perubahan formal) dan Constructive Change (perubahan inormal).

1. Direct change (perubahan formal) 
Direct change atau perubahan formal adalah perubahan yang diajukan dalam bentuk tertulis, yang diusulkan kepada kontraktor untuk merubah ruang lingkup kerja, waktu pelaksanaan, biaya-biaya atau hal-hal lain yang berbeda yang telah dispesifikasikan dalam kontrak (Gilbreath, 1992).

2. Constructive change (perubahan informal) Constructive changes adalah tindakan informal yang mengesahkan ataumemerintahkan suatu modifikasi di lapangan yang terjadi oleh karena kesalahan dalam melakukan tindakan.

Secara garis besar, change order dapat memberikan dampak langsung pada proyek terhadap :

1. Biaya proyek, menurut Barrie dan Paulson (1992) yang terdiri dari biaya langsung, biaya perpanjangan waktu, dan biaya dampak (impact cost).

2. Termin waktu proyek.

\section{METODE PENELITIAN}

\subsection{Bagan Alir Penelitian}

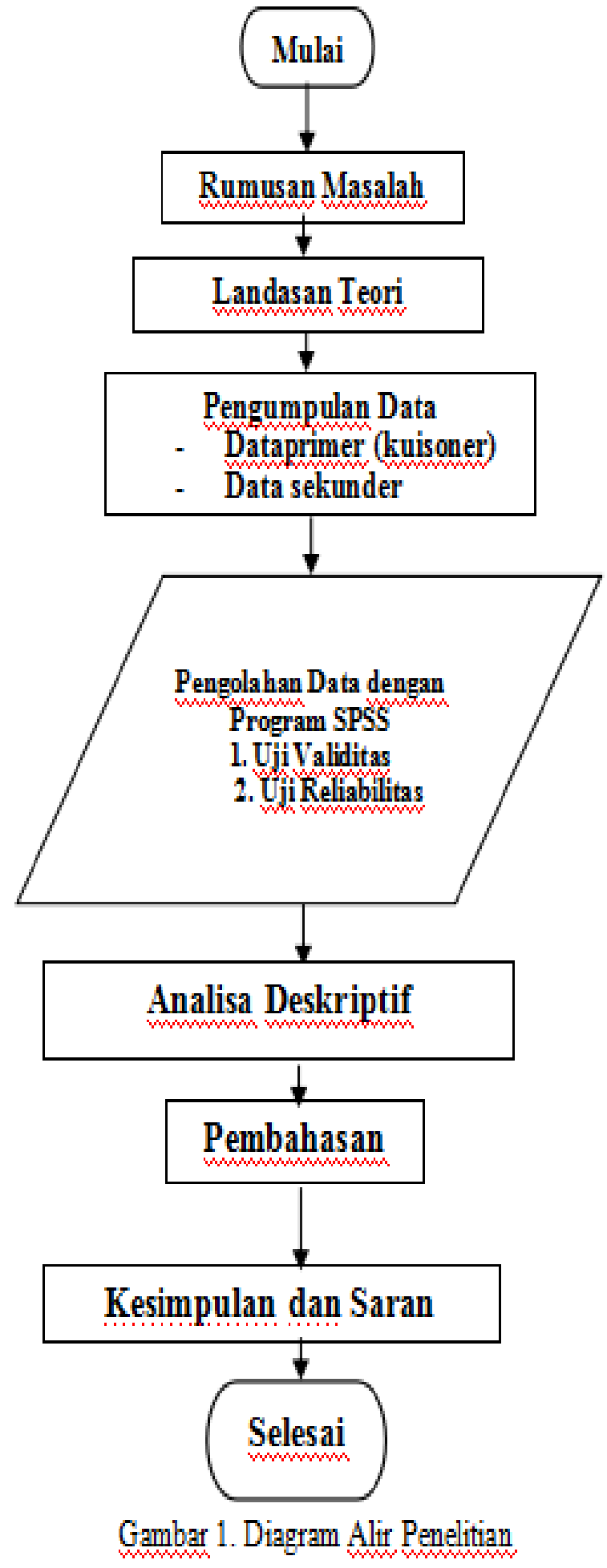

Objek penelitian adalah kontraktor jalan yang pernah mengerjakan proyek konstruksi jalan di Sumatera Barat dalam kurun waktu 10 (sepuluh) tahun terakhir. Penelitian ini akan dilakukan dengan cara menyebarkan kuesioner kepada 
perusahan kontraktor jalan yang mempunyai kantor di Padang yang pernah mengerjakan proyek konstruksi jalan di Sumatera Barat. Untuk itu responden yang di ambil dalam pengisian kuesioner kontraktor jalan yang kantornya berada di Padang yang tergabung dalam anggota GAPENSI (Gabungan Pelaksana Konstruksi Nasional Indonesia) yaitu berupa kumpulan pertanyaan yang diajukan secara tertulis kepada seorang responden, dan cara menjawabnya juga dilakukan dengan tertulis.

\subsection{Perancangan Kuesioner}

Tabel 1. Kuesioner

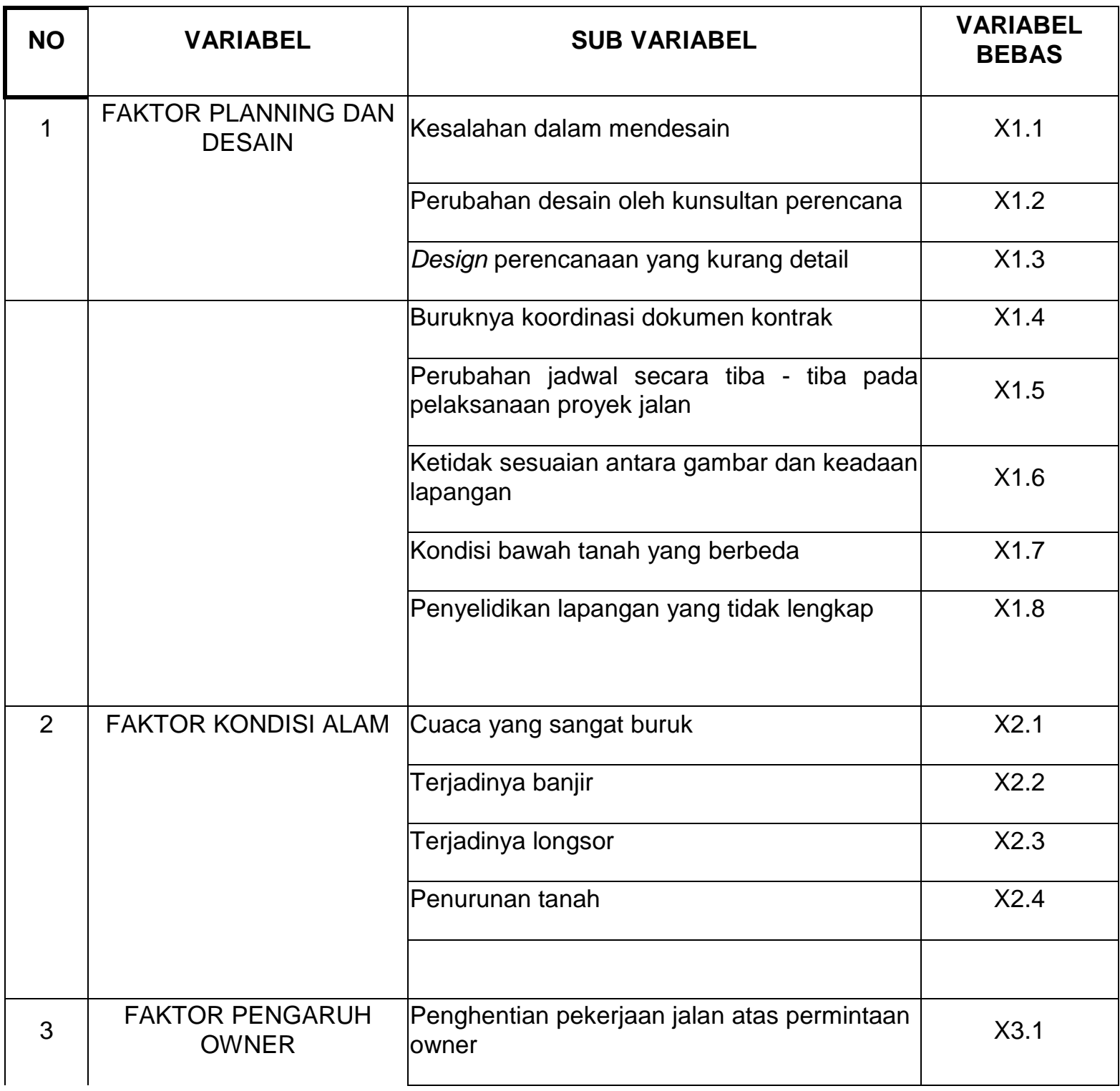




\begin{tabular}{|c|c|c|c|}
\hline & & $\begin{array}{l}\text { Percepatan waktu pelaksanaan pekerjaan } \\
\text { karena permintaan owner agar cepat selesai }\end{array}$ & \multirow[t]{2}{*}{ X3.2 } \\
\hline & & $\begin{array}{l}\text { Penundaan waktu pelaksanaan pekerjaan } \\
\text { karena permintaan owner }\end{array}$ & \\
\hline & & $\begin{array}{l}\text { Adanya permintaan perubahaan material oleh pihak } \\
\text { owner }\end{array}$ & X3.4 \\
\hline & & Adanya permintaan perubahan mutu oleh owner & X3.5 \\
\hline & & Perubahan spesifikasi teknis item pekerjaan & X3.6 \\
\hline \multirow[t]{11}{*}{4} & \multirow[t]{11}{*}{$\begin{array}{c}\text { FAKTOR } \\
\text { PENGARUH } \\
\text { KONTRAKTOR }\end{array}$} & $\begin{array}{l}\text { Kurangnya pengontrolan oleh kontraktor pada } \\
\text { pelaksanaan konstruksi jalan }\end{array}$ & X4.1 \\
\hline & & $\begin{array}{l}\text { Jadwal mulai kerja kontraktor lebih lambat dari jadwal } \\
\text { perencanaan }\end{array}$ & $X 4.2$ \\
\hline & & \begin{tabular}{|llll} 
Ketidak sesuaian & Jadwal & kontraktor dengan \\
subkontraktor & & & \\
\end{tabular} & X4.3 \\
\hline & & $\begin{array}{l}\text { Terjadinya keterlambatan karena adanya pekerjaan } \\
\text { yang diulang. }\end{array}$ & X4.4 \\
\hline & & $\begin{array}{l}\text { Penggantian mandor yang dilakukan kontraktor karena } \\
\text { pekerjaan tidak sesuai dengan kontrak }\end{array}$ & $\times 4.5$ \\
\hline & & Pengendalian material yang kurang baik & X4.6 \\
\hline & & $\begin{array}{l}\text { kurangnya team work kontraktor dalam pelaksanaan } \\
\text { pekerjaan }\end{array}$ & X4.7 \\
\hline & & $\begin{array}{l}\text { Kurangnya komunikasi antara pelaksana lapangan } \\
\text { dengan konsultan pengawas/perencana }\end{array}$ & $X 4.8$ \\
\hline & & Perubahan metoda kerja & $\times 4.9$ \\
\hline & & $\begin{array}{l}\text { Kesalahan dan kelalaian dalam perhitungan estimasi } \\
\text { volume }\end{array}$ & $X 4.10$ \\
\hline & & $\begin{array}{l}\text { Pengambilan keputusan yang kurang cepat oleh } \\
\text { kontraktor }\end{array}$ & $X 4.11$ \\
\hline 5 & $\begin{array}{l}\text { FAKTOR } \\
\text { PENYEBAB }\end{array}$ & $\begin{array}{l}\text { Perselisihan antara tenaga kerja baik itu kontraktor } \\
\text { konsultan maupun owner }\end{array}$ & $\times 5.1$ \\
\hline
\end{tabular}




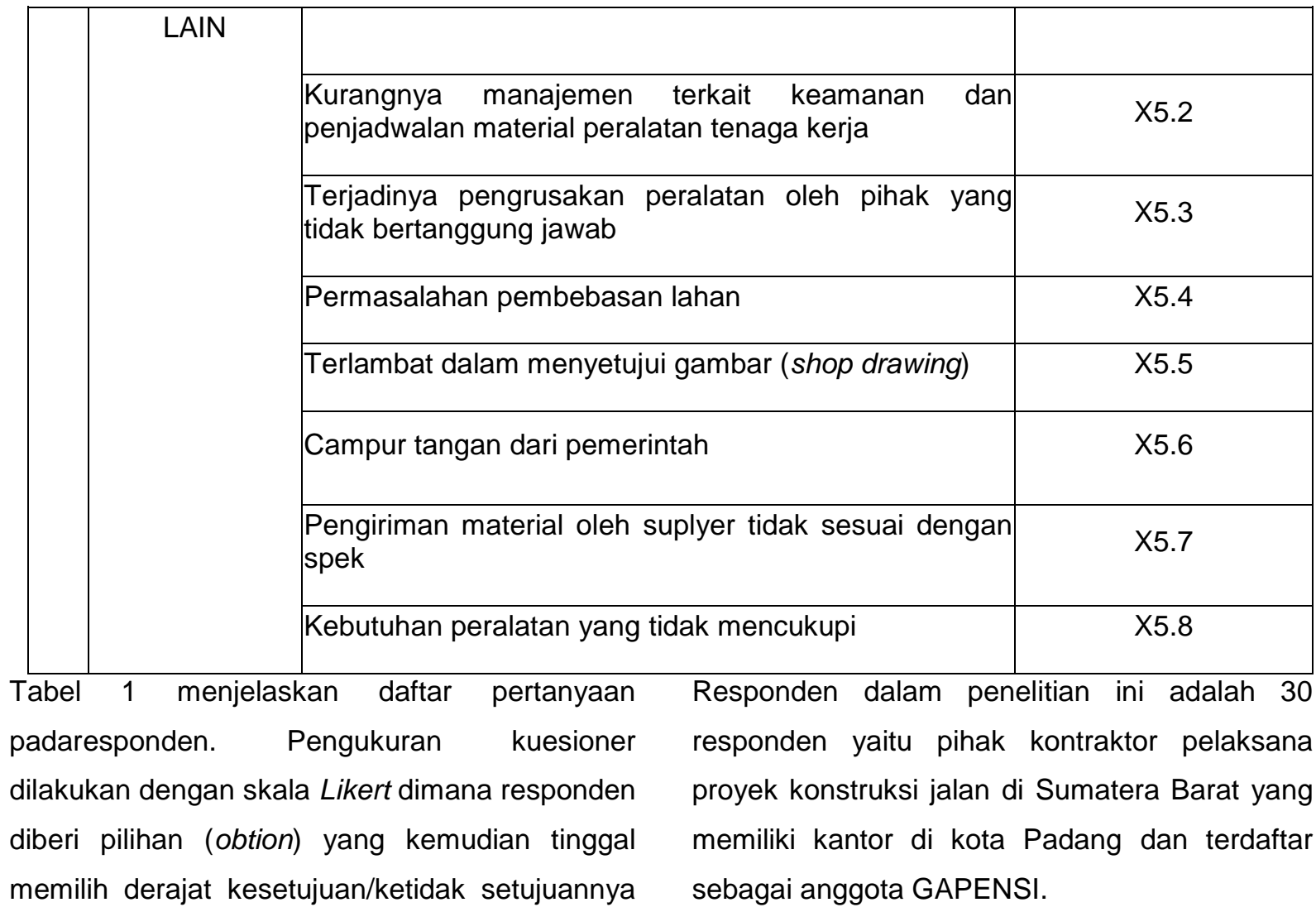
atas pertanyaan yang diajukan.

a. Jawaban sangat berpengaruh diberi nilai 5

b. Jawaban berpengaruh diberi nilai4

C. Jawaban cukup berpengaruh diberi nilai 3

d. Jawaban kurang berpengaruh diberi nilai 2

e. Jawaban tidak berpengaruh diberi nilai 1

Setelah data terkumpul, selanjutnya dilakukan pengolahan data yang bertujuan untuk mencari variabel dominan pada variabel-variabel yang mempengaruhi penyebab terjadinya change order pada proyek konstruksi jalan di Sumatera Barat. Pengolahan data dilakukan dengan menggunakan program statistik SPSS (Statistical Program for Social Science) versi23.0, meliputi: Uji validitas, Uji reliabilitas uji normalitas, uji korelasi, dan analisa Deskriptif.

\section{HASIL DAN PEMBAHASAN}

\subsection{Deskripsi Lokasi Penelitian}

\subsection{Deskripsi Responden}

Karakteristik responden diklasifikasikan berdasarkan usia ( 20-30 tahun 15 orang, 31-40 tahun 8 orang, 41-50 tahun 3 orang, dan besar dari 50 tahun 4 orang), jabatan responden (Direktur 17\%, Project Manager 24\%, Site Manager 20\%,General Superintenden $7 \%$, Quality Control 3\%, Quantity Engineer 7\%, staff teknik $10 \%$, dan pelaksana $13 \%$.).

pendidikan terakhir (pendidikan S1 57\%, S2 $3 \%$ dan D3 40\%), dan pengalaman kerja (17\% responden memiliki pengalaman $<5$ tahun bekerja, 57\% responden memiliki pengalaman 5-10 tahun bekerja, $6 \%$ responden memiliki pengalaman 11-14 tahun bekerja, dan 20\% responden memiliki pengalaman >20 tahun bekerja).

\subsection{Uji Validitas dan Reliabilitas}

\subsubsection{Uji Validitas}

Menurut Arikunto (2010) validitas adalah 
suatu ukuran yang menunjukkan tingkat kevalidan atau kesahihan suatu instrumen. Uji validitas dilakukan dengan program SPSS v.23. Jika $r$ hitung $\geq r$ tabel $(0,361)$ maka angket dikatakan valid. Jika $r$ hitung $<r$ tabel maka angket dikatakan tidak valid. Dari 5 variabel dan 37 sub variabel yang tertera pada kuesioner dapat dinyatakan bahawa semua itemnya valid karena $r$ hitung $>$ dari $r$ tabel $(0,361)$.

\subsubsection{Uji Reliabilitas}

Uji reliabilitas adalah untuk mengetahui kekonsistenan jawaban seseorang terhadap pernyataan dari waktu ke waktu. Untuk mengukur reliabilitas dari waktu ke waktu maka digunakan rumus alpha cronbach yang diolah dengan program SPSS.

Kriteria pengujian ini adalah jika nilai koefisien cronbach alpha $\left(r_{11}\right)>0.90$ maka reliabilitas sempurna. Jika alpha antara 0.700.90 maka reliabilitas dikatakan tinggi. Jika alpha antara 0.50-0.70 maka reliabilitas moderat/sedang. Jika alpha < 0.50 maka reliabilitas rendah. Jika alpha rendah, kemungkinan satu atau beberapa item tidak reliable.

Hasil uji reliabilitas pada penelitian adalah sebagai berikut:

\section{Tabel 2. Hasil Uji Reliabilitas}

\subsection{Uji Korelasi Pearson Product Moment}

Uji Korelasi Pearson Product Moment adalah salah satu dari beberapa jenis uji korelasi yang digunakan untuk mengetahui tingkat keeratan hubungan antar variabel.

Tabel 3. Hasil Pengujian Variabel Terkorelasi

\begin{tabular}{|c|c|c|c|l|}
\hline no & $\begin{array}{c}\text { VARIA } \\
\text { BEL }\end{array}$ & $\begin{array}{c}\text { SUB } \\
\text { VARIABEL }\end{array}$ & $\begin{array}{c}\text { NILAI } \\
\text { KORE } \\
\text { LASI }\end{array}$ & KET \\
\hline
\end{tabular}

\begin{tabular}{|c|c|c|c|c|c|}
\hline No & \multicolumn{2}{|c|}{ Variabel } & & $\begin{array}{l}\text { onbacl } \\
\text { Alpha }\end{array}$ & Keterangan \\
\hline 1 & \multicolumn{2}{|c|}{$\begin{array}{l}\text { Faktor planning } \\
\text { dan desain }(X 1)\end{array}$} & & 0.756 & Tinggi \\
\hline 2 & \multicolumn{2}{|c|}{$\begin{array}{l}\text { faktor kondisi } \\
\text { alam(X2) }\end{array}$} & & 0.865 & Tinggi \\
\hline 3 & \multicolumn{2}{|c|}{$\begin{array}{c}\text { faktor pengaruh } \\
\text { owner(X3) }\end{array}$} & & 0.619 & Sedang \\
\hline 4 & \multicolumn{2}{|c|}{$\begin{array}{l}\text { faktor pengaruh } \\
\text { kontraktor(X4) }\end{array}$} & & 0.785 & Tinggi \\
\hline 5 & \multicolumn{2}{|c|}{$\begin{array}{l}\text { faktor penyebab } \\
\text { lain(X5) }\end{array}$} & \multicolumn{2}{|r|}{0.776} & Tinggi \\
\hline 1 & \multirow[t]{3}{*}{$\begin{array}{c}\text { Planni } \\
\text { ng dan } \\
\text { Desain } \\
\text { (X1) }\end{array}$} & \multicolumn{2}{|c|}{$\begin{array}{l}\text { kesalahan } \\
\text { dalam } \\
\text { mendesain } \\
(\mathrm{X} 1.1)\end{array}$} & 0,406 & cukup kuat \\
\hline 2 & & $\begin{array}{r}\text { perubah } \\
\text { desain o } \\
\text { konsult } \\
\text { perenca } \\
\text { (X1.2 }\end{array}$ & & 0,507 & cukup kuat \\
\hline 3 & & $\begin{array}{r}\text { ketidakse } \\
\text { an anta } \\
\text { gamba } \\
\text { denga } \\
\text { kondis } \\
\text { lapang } \\
\text { (X1.6 }\end{array}$ & & 0,595 & cukup kuat \\
\hline 4 & $\begin{array}{c}\text { Kondisi } \\
\text { Alam } \\
\text { (X2) }\end{array}$ & $\begin{array}{r}\text { cuaca ya } \\
\text { sangat b } \\
(\times 2.1\end{array}$ & & 0,541 & cukup kuat \\
\hline 5 & & $\begin{array}{l}\text { terjadin } \\
\text { banjir }(X\end{array}$ & & 0,416 & cukup kuat \\
\hline 6 & & $\begin{array}{c}\text { terjadir } \\
\text { longsc } \\
\text { (X2.1 }\end{array}$ & & 0,646 & kuat \\
\hline 7 & & $\begin{array}{l}\text { penurul } \\
\operatorname{tanah}(X\end{array}$ & & 0,442 & cukup kuat \\
\hline
\end{tabular}




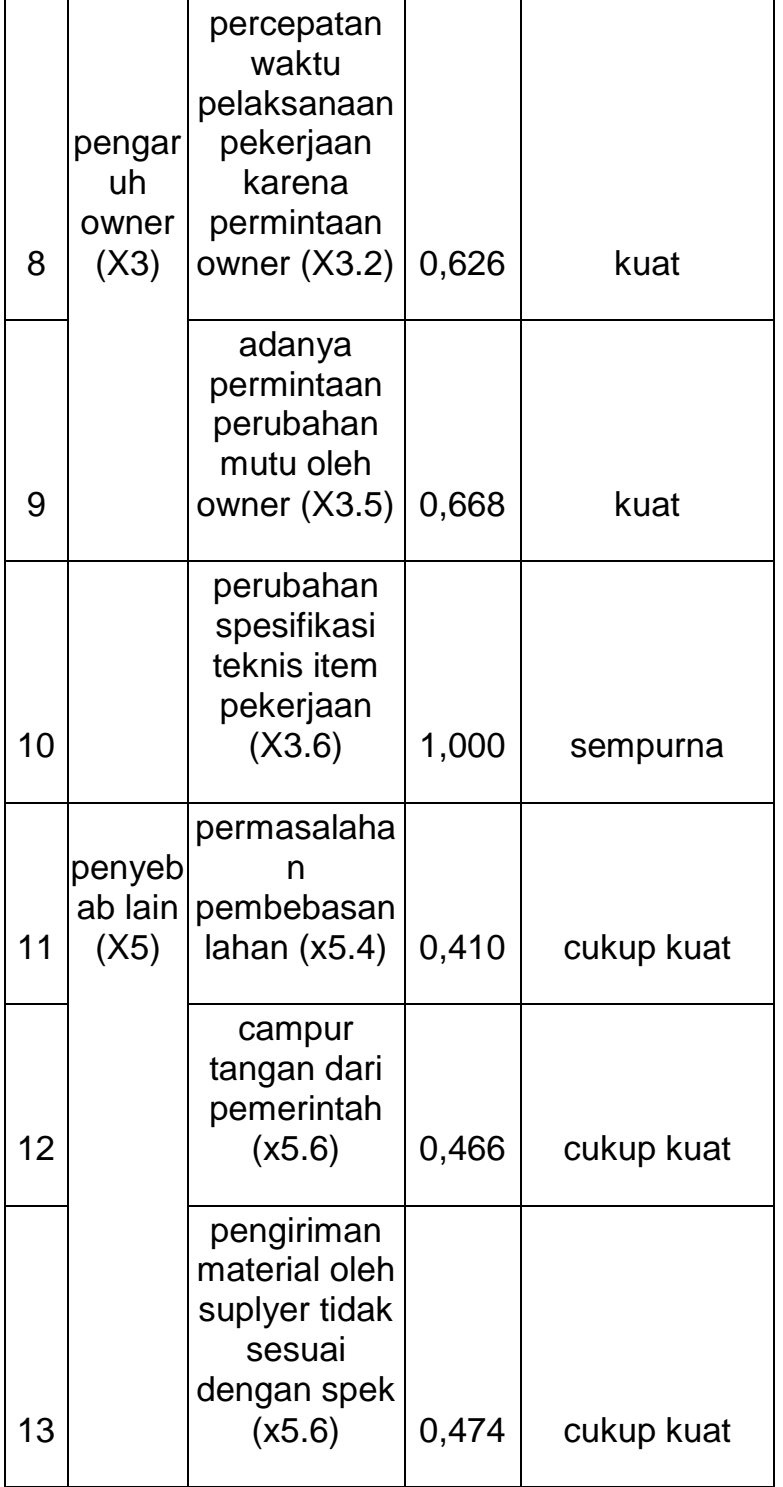

Dari 37 sub variabel pada 5 variabel didapat 13 sub variabel yang terkorelasi, sehingga 13 sub variabel ini merupakan yang akan dilanjutkan untuk uji analisa deskriptif.

\subsection{Analisa Deskriptif}

Analisa ini bertujuan untuk menyimpulkan subfaktor yang paling berpengaruh berdasarkan variabel planning dan desain, kondisi alam, pengaruh dari owner, dan faktor penyebab lain. Berikut akan adalah hasil rekapitulasi analisis deskriptif dilihat dari nilai mean tertinggi pada item pernyataan dalam tiap-tiap variabel $X$.

\section{Tabel 4 Hasil pengujian statistik deskriptif}

\begin{tabular}{|c|c|c|c|c|}
\hline $\begin{array}{l}N \\
O\end{array}$ & $\begin{array}{l}\text { VARI } \\
\text { ABEL }\end{array}$ & $\begin{array}{l}\text { SUB } \\
\text { VARIABEL } \\
\text { YANG } \\
\text { SANGAT } \\
\text { BERPENGA } \\
\text { RUH }\end{array}$ & $\begin{array}{c}\text { MEA } \\
\mathrm{N}\end{array}$ & $\begin{array}{c}\text { PERSE } \\
\text { NTASE } \\
(\%)\end{array}$ \\
\hline 1 & (XI) & $\begin{array}{l}\text { Ketidak } \\
\text { sesuaian } \\
\text { antara } \\
\text { gambar } \\
\text { dengan } \\
\text { keadaan } \\
\text { lapangan } \\
\text { ( X1.6) }\end{array}$ & 4.4 & $88 \%$ \\
\hline 2 & (X2) & $\begin{array}{l}\text { Faktor } \\
\text { terjadinya } \\
\text { longsor } \\
\text { (X2.3) }\end{array}$ & 4.03 & $80,6 \%$ \\
\hline 3 & (X3) & $\begin{array}{l}\text { Faktor } \\
\text { percepatan } \\
\text { waktu } \\
\text { pelaksanaan } \\
\text { pekerjaan } \\
\text { karena } \\
\text { permintaan } \\
\text { owner (X3.2) }\end{array}$ & 4.13 & $82,6 \%$ \\
\hline 4 & (X5) & $\begin{array}{l}\text { Faktor } \\
\text { permasalah } \\
\text { an } \\
\text { pembebasa } \\
n \text { lahan } \\
(\mathrm{X} 5.4)\end{array}$ & 4.2 & $84 \%$ \\
\hline
\end{tabular}

Tabel diatas merupakan hasil dari analisa deskriptif mewakili setiap variabel yang ada. Dimana faktor yang diambil adalah faktor yang memiliki nilai mean paling tinggi dan terkorelasi diantara faktor-faktor yang lain dalam setiap variabelnya. Sehingga didapatkan 4 faktor dominan yang menyebabkan change order pada proyek konstruksi jalan di Sumatera Barat setelah pengujian korelasi dan uji analisa deskriptif.

\subsection{Pembahasan}

Dari hasil pengolahan analisis deskriptif yang telah dilakukan, dengan melihat nilai mean 
tertinggi mewakili setiap variabel yang dianalisis, diperoleh hasil bahwa faktor-faktor dominan penyebab change order pada proyek konstruksi jalan di Sumatera Barat adalah:

a. Ketidak sesuaian antara gambar dengan keadaan lapangan (X1.6) pada variabel faktor planning dan desain dengan nilai mean 4,4.

b. Terjadinya longsor (X2.3) pada variabel kondisi alam dengan nilai mean 4,03

c. Faktor percepatan waktu pelaksanaan pekerjaan karena permintaan owner (X3.2) pada variabel pengaruh dari owner dengan nilai mean 4,13 .

d. Faktor permasalahan pembebasan lahan (X5.4) pada variabel penyebab lain dengan nilai mean 4,2 .

Sehingga didapat variabel yang paling dominan sebagai penyebab terjadinya change order yang dialami oleh pihak kontraktor pada proyek konstruksi jalan di Sumatera Barat adalah faktor planning dan desain yaitu ketidak sesuaian antara gambar dengan kondisi lapangan dengan nilai mean 4,4.

Sehingga dapat disimpulkan besar pengaruh change order dilihat dari nilai mean pada proyek konstruksi jalan di Sumatera Barat adalah sebesar $88 \%$. Serta nilai pearson korelasi sebesar 0.595 berada diantara 0,410,60 maka dapat dikatakan bahwa tingkat kesepakatan/keselarasan diantara responden adalah cukup kuat dengan nilai signifikannya sebesar 0,001<0,05 yang disyaratkan.

\section{Kesimpulan}

1. Dengan mengetahui faktor-faktor penyebab terjadinya change order pada proyek konstruksi jalan di Sumatera Barat, diharapkan dapat memberikan masukan kepada a. pihak kontraktor dengan kualifikasi menengah (M1 atau M2) agar dapat dijadikan sebagai pedoman untuk meminimalisir terjadinya faktor tersebut pada proyek konstruksi jalan di Sumatera Barat. Kontraktor harus teliti saat study kelayakan dan pada ssat proses penjelasan kepada pemilik, kontraktor dapat meyakinkan kepada owner kalau pekerjaan itu layak untuk dilaksanakan dan tidak merugikan owner.

b. Terhadap pihak konsultan perencana diharapkan dengan mengetahui adanya change order, pada saat proses perencanaan konsultan perencana harus menyesuaiankan kondisi lapangn dengan gambar, dan diharapkan konsultan tidak memakai gambar proyek lain agar tidak terjadi permasalahan change order. Dan konsultan benar-benar mempertanggung jawabkan gambar agar tidak merugikan banyak pihak.

c. Terhadap pihak owner sebelum mengambil tindakan seperti mempercepat waktu pelaksanaan, owner harus mengetahui dampak dari hal tersebut. Sehingga pada pelaksanaan jika terjadi dampak yang tidak diinginkan akan memberikan resiko kepada kontraktor dan pihak yang berkaitan lainnya.

d. Terhadap kepala daerah memberikan kejelasan dan pengertian kepada masyarakat yang lahannya terpakai untuk pembangunan jalan agar pelaksanaan konstruksi jalan berjalan dengan lancar.

2. Setelah diketahuinya faktor yang paling dominan diharapkan perusahaan kontraktor melakukan pengawasan oleh orang-orang yang berpengalaman dan profesional.

3. Penelitian ini juga diharapkan dapat memberikan masukan kepada peneliti selanjutnya untuk mencari lebih detail faktor- 
faktor penyebab change order pada proyek konstruksi jalan di Sumatera Barat

4. Menghubungkan keterkaitan antara faktorfaktor penyebab change order pada proyek konstruksi jalan di Sumatera Barat terhadap biaya karena faktor penyebab change order ini berpengaruh terhadap biaya.

5. Mencari solusi agar faktor penyebab change order ini kemungkinan terjadinya dapat diminimalisirkan.

\section{DAFTAR PUSTAKA}

Dewantoro, Lendra, Abriyan Prayudi, "Penyebab dan Pengaruh Contract Change Order Pada Proyek Peningkatan Jalan (Study Kasus Paket Kegiatan Jalan Pasar Panas-Bentot 2 Multiyears)" Jurnal Teknika, Vol. 1,

Fakhrizal"Identifikasi Penyebab Dan Dampak Change Order Terhadap Biaya dan Kualitas Pada Proyek Gedung Di Kota Padang“ Jurnal Penelitian, Program Study Teknik Sipil, Universitas BungHatta, 2013.

Michella Beatrix, dkk "analisa pengaruh change order terhadap biaya, waktu, dan mutu proyek konstruksi di Surabaya" Program Study Pasca Sarjana Teknik Sipil, Jurusan Teknik, Institut Sepuluh November, 2014.

Ningsih, Ir. Syahrudin, Nurul Wardhani"Identifikasi dan Analisis Penyebab dan Akibat Contract Change Order Terhadap Biaya dan Waktu Pada Proyek
Nurlaela, Sri Dewi" Analisis Faktor -Faktor Penyebab Change Order dan Pengaruhnya Yang Dominan Terhadap Kinerja Biaya Pelaksanaan Proyek Konstruksi Dilingkungan Pemerintahan Provinsi Maluku Utara" Jurnal IImiah MEDIA ENGINEERING Vol. 3, No. 1, Maret 2013 ISSN 2087-9334 (42-48), 2013.

Prianto"Analisa Faktor Penyebab Pekerjaan Perubahan Pada Proyek konstruksi di Kota Malang”. Jurnal Penelitian, 2013.

Qarnain Dzul "analisa faktor penyebab dan akibat contract change order terhadap biaya dan waktu pada proyek konstruksi jalan di Sulawesi Selatan"Jurnal Penelitian Tugas Akhir, Program Study Teknik Sipil, Universitas Hasanuddin , 2017.

Sapultte"analisa penyebab dan pengaruh change order pada proyek infrastruktur dan bangunan gedung diambon“. Jurnal TEKNOLOGI, Volume 6 Nomor 2, 2009;627Oktobe 3301 190,9ipn 11-19, 2017.

Silviane Anggraene"Analisa Penyebab dan Dampak Change Order Pada Proyek Peningkatan Jalan (Study Kasus Peningkatan Jalan Katingan)" Skripsi, Program Study Teknik Sipil, Jurusan Teknik, Universitas Palangkaraya, 2012.

Sulistio, dkk"Analysis and Evaluation Change Order In Flexible Pavement Road Project In East Kalimantan". Jurnal Penelitian, Media Komunikasi Teknik Sipil tahun 16, no 1, Februari, 2008.

Wibowo Andi, dkk,"Model Pengaruh Change Order Pada Kehilangan Produktivitas dan Performa Proyek konstruksi Jalan Dari Perspektif Sistim Teori" Jurnal Penelitian, Konstrå899.Jurnal Penelitian, 2014 
